\title{
Investigasi dan Optimasi Parameter Proses Micro Friction Stir Spot Welding Material A1100/Cu1100P Menggunakan Metode Taguchi
}

\author{
P.Rupajati1 ${ }^{1, \mathrm{a}} *$, A.S.Baskoro ${ }^{2, \mathrm{~b}}$, Winarto $^{3, \mathrm{c}}$, Matsuani $^{4, \mathrm{~d}}$ \\ ${ }^{a}$ Program Studi Teknik Mesin, Institut Teknologi Indonesia \\ J1. Raya Puspiptek Serpong, Kota Tangerang Selatan, 15314 \\ ${ }^{\mathrm{b}}$ Departemen Teknik Mesin, Fakultas Teknik, Universitas Indonesia \\ Kampus Baru UI Depok, 16424 \\ ${ }^{\mathrm{c}}$ Departemen Teknik Metalurgi dan Material, Fakultas Teknik, Universitas Indonesia \\ Kampus Baru UI Depok, 16424 \\ ${ }^{\mathrm{d}}$ Program Studi Teknik Otomotif, Institut Teknologi Indonesia \\ Jl. Raya Puspiptek Serpong, Kota Tangerang Selatan, 15314 \\ ${ }^{a)}$ pathya.rupajati@iti.ac.id, ${ }^{b)} \underline{\text { ario@eng.ui.ac.id }},{ }^{c} \underline{\text { winarto@metal.ui.ac.id, }}{ }^{a)}$ matsuani@iti.ac.id
}

\begin{abstract}
Abstrak
Penelitian ini bertujuan untuk melakukan optimasi tensile shear load hasil pengelasan micro friction stir welding ( $\mu$ FSSW) pada material AA1100 dan Cu1100P menggunakan metode Taguchi. Rancangan percobaan yang digunakan dalam penelitian ini adalah matriks orthogonal array $\mathrm{L}_{8}$ dengan memvariasikan parameter proses pengelasan yaitu dwell time dan plunge depth yang memiliki masingmasing empat level dan dua level. Sedangkan variabel konstan yang digunakan adalah tool rotational speed sebesar $33.000 \mathrm{rpm}$. Hasil penelitian menunjukkan bahwa optimasi parameter pengelasan menggunakan metode Taguchi mampu memberikan seting kombinasi optimum untuk mendapatkan nilai tensile shear load optimal. Dari parameter pengelasan $\mu$ FSSW, parameter yang memiliki kontribusi terbesar dalam meningkatkan tensile shear load hasil pengelasan micro friction stir spot welding adalah dwell time, yang menghasilkan tensile shear load sebesar 265,12 $\mathrm{N}$ dengan seting kombinasi dwell time pada $5 \mathrm{~s}$ dan plunge depth pada $0,7 \mathrm{~mm}$. Hasil struktur mikro juga menunjukkan terlihat adanya flash dan hook defect, tetapi tidak menujukkan adanya intermetallic compound dan crack.
\end{abstract}

Kata kunci: A1100, $\mu \mathrm{FSSW}$, Taguchi, Dwell time, Plunge Depth

\begin{abstract}
This study aims to optimize the tensile shear load of the micro friction stir welding on A1100 and Cu1100P materials using the Taguchi method. The experimental design used in this study is the $L_{8}$ orthogonal array matrix by varying the welding process parameters dwell time and plunge depth which have four levels and two levels respectively, while the constant variable used is the rotational speed tool of 33,000 rpm. The results shows that the optimization of $\mu F S S W$ parameters using the Taguchi method was able to provide optimum combination settings to obtain optimal tensile shear load. The parameter process that has the biggest contribution in increasing the tensile shear load welding results from micro friction stir spot welding is the dwell time, which results in a tensile shear load of $265.12 \mathrm{~N}$ with the setting of the dwell time combination at $5 \mathrm{~s}$ and plunge depth at $0,7 \mathrm{~mm}$. The results of the microstructure also showed no indication intermetallic compund and crack in the nugget zone.
\end{abstract}

Keywords: A1100, $\mu$ FSSW, Taguchi, Dwell time, Plunge Depth

\section{PENDAHULUAN}

Material yang saat ini banyak digunakan untuk membuat komponen otomotif dan industri manufaktur adalah aluminum alloy di mana aluminium dengan ketebalan di bawah $1 \mu \mathrm{m}$, masih relatif sulit dilakukan pada proses micro friction stir spot welding ( $\mu \mathrm{FSSW}$ ). Salah satu metode pengelasan yang digunakan untuk menyambungkan material tipis aluminium ini adalah micro friction stir spot welding ( $\mu \mathrm{FSSW}$ ) yang merupakan turunan dari friction stir welding (FSW) yang pertama kali ditemukan oleh TWI pada tahun 1991 [1]. Konsep dari pengelasan friction stir spot welding adalah metode penyambungan dua buah material logam dengan menggunakan energi panas 
dihasilkan dari perubahan energi mekanik kedalam energi panas pada bidang interface benda kerja karena adanya gesekan selama gerak putar di bawah tekanan atau gesekan [2]. Salah satu kelebihan yang dimiliki pengelesan friction spot adalah tidak mengalami melting pada saat pengelasan, dan dapat mengurangi terjadinya voids dan cacat pengelasan. Beberapa penelitian mengenai $\mu$ FSSW sudah mulai dikembangkan, diantaranya yaitu pada material aluminium A1100 telah dilakukan dengan parameter proses yang digunakan adalah tool tilt angle, kecepatan spindle, dan kecepatan pengelasan [3]. Proses pengelasan FSSW pada material yang berbeda juga sudah mulai dikembangkan, diantaranya pengaruh rotational speed, dwell time, plunge depth, pin diameter, dan tilt angle terhadap struktur mikro dan sifat mekanis pada material aluminium dan tembaga [4]. Metode Taguchi merupakan salah satu metode yang efektif untuk mengendalikan kualitas produk secara off-line, yaitu usaha pengendalian atau perbaikan kualitas yang dimulai dari perancangan hingga pemrosesan produk, dimana bertujuan juga untuk menghindari trial and error dari suatu ekskperimen. Metode Taguchi banyak digunakan sebagai salah satu desain eksperimen, diantaranya parameter pengelasan friction stir spot welding (FSSW) pada material AA3003-H12 menggunakan metode Taguchi dengan rancangan percobaan $\mathrm{L}_{9}$. Parameter pengelasan yang digunakan antara lain, tool rotational speed, tool plunge depth dan dwell time. Variabel respon yang diamati adalah tensile shear load [5]. Metode untuk mengetahui kombinasi optimal suatu parameter proses, jika memiliki variable respons lebih dari satu, digunakan response surface methodology (RSM), fuzzy logic, grey fuzzy logic, genetic alghorithm, artificial neural network. Variabel respon seperti shear strength pada proses pengelasan $\mu \mathrm{FSW}$ pada aluminium A1100 menggunakan response surface methodology berhasil diteliti [6]. Hasil penelitian tersebut menunjukkan bahwa pin diameter dan plunge speed merupakan parameter yang paling signifikan dalam meningkatkan shear strength. Selanjutnya beberapa peneliti lainnya telah melakukan optimasi parameter proses pengelasan FSW dan FSSW baik pada similar maupun dismilar material [7], [8], [9]. Penelitian ini bertujuan untuk menginvestigasi dan menentukan kombinasi optimal pada parameter proses pengelasan $\mu$ FSSW pada material aluminium A1100 dan tembaga dengan parameter pengelasan yang digunakan plunge depth dan dwell time, masing-masing terdiri dari 4 dan 3 level menggunakan metode Taguchi.

\section{METODE PENELITIAN}

Pada penelitian ini material A1100 dan Cu1100P yang digunakan dalam proses pengelasan micro friction stir spot welding ( $\mu \mathrm{FSSW})$, masing-masing memiliki dimensi $10 \mathrm{~mm}$ x $20 \mathrm{~mm}$ x 0,42 mm seperti yang ditunjukkan pada Gambar 1a, sedangkan komposisi kimia material A1100 dan Cu1100P ditunjukkan pada Tabel 1 dan 2. Material pahat yang digunakan terbuat dari baja HSS yang memiliki diameter dan tinggi pin sebesar $0,238 \mathrm{~mm}$ dan 2,70 $\mathrm{mm}$, sedangkan diameter dan tinggi shoulder adalah 4,6 $\mathrm{mm}$ dan $5 \mathrm{~mm}$ seperti yang ditunjukkan pada Gambar 1b. Mesin friction stir spot welding pada penelitian ini menggunakan mesin tensile test yang merupakan hasil modifikasi dari mesin frais EMCO CNC TU-3A yang memiliki ketelitian sebesar 0,01 $\mathrm{mm}$, sedangkan spindle yang digunakan berasal dari mesin bor turner Maktec tipe MT912 dengan spesifikasi die grinder $6 \mathrm{~mm}$ dan kecepatan putar spindle tanpa beban sebesar $33.000 \mathrm{rpm}$. Pengujian tensile shear strength digunakan mesin tensilon A\&D dengan kapasitas $50 \mathrm{kN}$. Pada saat pengelasan $\mu$ FSSW berlangsung, material tembaga berada di atas material aluminium A1100. Parameter proses pengelasan $\mu$ FSSW yang digunakan pada penelitian ini yaitu $d w e l l$ time $(4,5,6$ dan $7 \mathrm{~s})$ dan plunge depth (0,65 dan $0,7 \mathrm{~mm}$ ) yang ditunjukkan pada Tabel 3.

Tabel 1. Komposisi Kimia Material A1100 dan $\mathrm{Cu}$

\begin{tabular}{lcccccc} 
Material & \%Al & $\% \mathbf{C u}$ & $\% \mathrm{Mn}$ & $\boldsymbol{\%} \mathbf{Z n}$ & $\begin{array}{c}\% \mathbf{S i} \\
+ \\
\mathbf{F e}\end{array}$ & $\begin{array}{c}\% \\
\text { others }\end{array}$ \\
\hline $\begin{array}{l}\text { Aluminium } \\
\text { A1100 }\end{array}$ & \multirow{2}{*}{99} & 0,2 & 0,05 & 0,1 & 0,95 & 0,1 \\
$\max$ & $\max$ & $\max$ & $\max$ & $\max$ \\
\hline
\end{tabular}

Tabel 2. Komposisi Kimia Material AA1 100 dan $\mathrm{Cu}$

\begin{tabular}{ccccccc}
\hline Material & \%Cu & \%Al & \%Fe & \%Ni & \%Pb & \%Sn \\
\hline $\mathrm{Cu} 1100 \mathrm{P}$ & 99 & - & - & - & - & - \\
\hline
\end{tabular}

Tabel 3. Parameter Pengelasan $\mu$ FSSW Beserta Levelnya

\begin{tabular}{ccccccccc}
\hline \multirow{2}{*}{ No } & $\begin{array}{c}\text { Parameter } \\
\text { Proses }\end{array}$ & \multirow{2}{*}{ unit } & \multirow{2}{*}{ Notasi } & \multicolumn{5}{c}{ Level } \\
\cline { 5 - 8 } $\mathbf{1}$ & Dwell time & s & A & 4 & 5 & 6 & 7 \\
\hline $\mathbf{2}$ & $\begin{array}{c}\text { Plunge } \\
\text { depth }\end{array}$ & mm & B & 0,65 & 0,7 & - & - \\
\hline
\end{tabular}

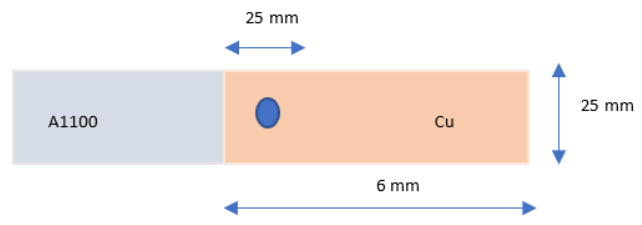

(a)

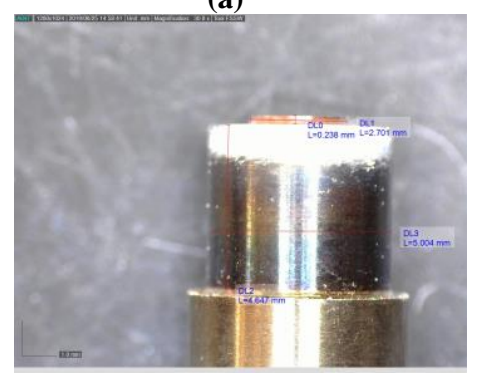

(b)

Gambar 1 (a) Skema Spesimen Pengelasan $\mu$ FSSW;

(b) Material Pahat 


\section{HASIL DAN PEMBAHASAN}

Pelaksanaan eksperimen dilakukan dengan mengkombinasikan parameter proses micro friction stir spot welding ( $\mu \mathrm{FSSW}$ ) yang terdapat pada mesin $C N C$ Freis yaitu: dwell time (A) dan plunge depth (B). Variabel respon yang diamati adalah tensile shear load. Tabel 4 dan Gambar 2 menunjukkan hasil pengujian tensile shear load dan rasio $\mathrm{S} / \mathrm{N}$ hasil dari pengelasan material ( $\mu \mathrm{FSSW})$ pada material aluminium A1100/Cu1100P yang dilakukan secara acak menggunakan rancangan percobaan $\mathrm{L}_{8}$ dengan software Minitab 16. Rasio S/N (Signal to Noise) digunakan untuk melakukan transformasi pengulangan data ke dalam suatu nilai yang merupakan ukuran variasi yang timbul. Selain itu, rasio S/N digunakan untuk memilih parameter proses-parameter proses yang memiliki kontribusi pada pengurangan variasi suatu respon. Perhitungan rasio $\mathrm{S} / \mathrm{N}$ tergantung pada karakteristik kualitas dari respon. Perhitungan rasio $\mathrm{S} / \mathrm{N}$ untuk tensile shear load, yang digunakan dalam penelitian ini adalah semakin besar semakin baik yang dihitung menggunakan persamaan 1 [10].

$$
\mathrm{S} / \mathrm{N}=-10 \log \left[\sum_{\mathrm{i}=1}^{\mathrm{n}} \frac{\left(1 / \mathrm{y}_{\mathrm{i}}{ }^{2}\right)}{\mathrm{n}}\right]
$$

Di mana $\mathrm{S} / \mathrm{N}$ adalah $\mathrm{n}$ adalah jumlah replikasi yang dilakukan pada saat eksperimen, $\mathrm{y}_{\mathrm{i}}$ adalah nilai dari tensile shear load dari setiap replikasi.

Tabel 4. Hasil Pengujian Tensile Shear Load pada Pengelasan $\mu$ FSSW Material Aluminium A1100/Cu1100P

\begin{tabular}{ccccc}
\hline $\begin{array}{c}\text { No. } \\
\text { Exp }\end{array}$ & $\begin{array}{c}\text { Dwell } \\
\text { time } \\
(\mathrm{s})\end{array}$ & $\begin{array}{c}\text { Plunge } \\
\text { depth } \\
(\mu \mathrm{m})\end{array}$ & $\begin{array}{c}\text { Tensile } \\
\text { shear } \\
\text { load } \\
(\mathrm{N})\end{array}$ & $\begin{array}{c}\text { Rasio S/N } \\
\text { tensile shear } \\
\text { load }\end{array}$ \\
\hline 1 & 4 & 0,65 & 120,37 & 41,61 \\
2 & 4 & 0,7 & 180,20 & 45,11 \\
3 & 5 & 0,65 & 150,88 & 43,57 \\
4 & 5 & 0,7 & 265,12 & 48,47 \\
5 & 6 & 0,65 & 103,98 & 40,39 \\
6 & 6 & 0,7 & 209,77 & 46,43 \\
7 & 7 & 0,65 & 73,91 & 37,37 \\
8 & 7 & 0,7 & 98,99 & 39,92 \\
\hline
\end{tabular}

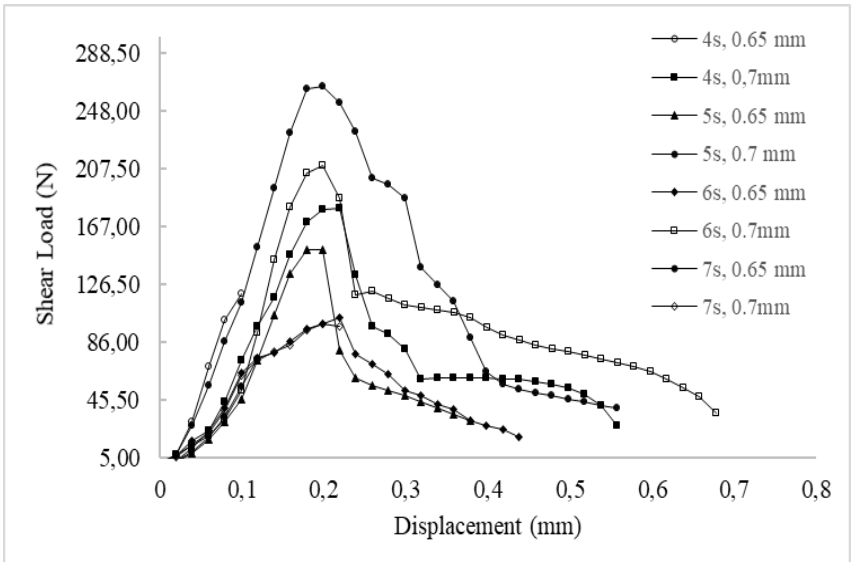

Gambar 2. Grafik Pengujian Tensile Shear Load Pada Pengelasan $\mu$ FSSW Material Aluminium A1100/Cu1100P

Hasil pengujian tensile shear load yang ditunjukkan pada Tabel 4 dan Gambar 2 menunjukkan bahwa secara keseluruhan nilai tensile shear load paling besar terdapat pada plunge depth dengan kedalaman $0,7 \mu \mathrm{m}$. Hal ini disebabkan plunge depth akan menghasilkan diameter pengelasan yang besar, yang akan cenderung meningkatkan tensile shear load $[5,11]$. Fenomena seperti ini mungkin terjadi karena peningkatan deformasi plastik material di sekitar nuget zone [12]. Pada kondisi plunge depth $0,65 \mathrm{~mm}$, nilai tensile shear load tertinggi sebesar 150,88 N pada dwell time $5 \mathrm{~s}$, sedangkan pada kondisi plunge depth 0,7 $\mathrm{mm}$, nilai tensile shear load tertinggi sebesar 265,12 N pada dwell time 5s. Hal ini menunjukkan bahwa nilai tensile shear load baik pada plunge depth $0,65 \mathrm{~mm}$ maupun $0,7 \mathrm{~mm}$ mengalami peningkatan dari $d w e l l$ time 4 s sampai dengan dwell time 5 s. Kemudian dari dwell time $5 \mathrm{~s}$ mulai mengalami penurunan signifikan. Walaupun dwell time yang tinggi menghasilkan bonding yang kuat sehingga meningkatkan tensile shear strength, akan tetapi dwell time juga dapat meningkatkan temperatur yang menyebabkan menurunnya kualitas dari pengelasan $[11,13,14]$.

Hasil eksperimen menggunakan metode Taguchi dengan rancangan percobaan $\mathrm{L}_{8}$ menunjukkan bahwa kombinasi parameter proses yang optimal dalam meningkatkan tensile shear load adalah dwell time di level 2 dan plunge depth di level 2 seperti yang ditunjukkan pada Tabel 5 dan Gambar 3. Analisis variansi (ANOVA) yang bertujuan untuk mengidentifikasi parameter proses yang memberikan kontribusi yang signifikan secara statistik memberikan gambaran yang jelas sejauh mana parameter proses mempengaruhi respon tensile shear load. Berdasarkan hasil analisis variansi (ANOVA) pada pengelasan $\mu$ FSSW material aluminium A1100/Cu1100P yang ditunjukkan pada Tabel 6, parameter proses dwell time dan plunge depth memiliki pengaruh yang signifikan terhadap respon tensile shear load yang ditunjukkan dari besarnya nilai $\mathrm{F}$ pada dwell time dan plunge depth yaitu masing-masing sebesar 15,48 dan 29,76 masih lebih besar dari $\mathrm{F}$ tabel, sedangkan yang memiliki 
kontribusi terbesar dalam mempengaruhi respon tersebut adalah $d$ well time dengan persentase kontribusi sebesar $54,85 \%$.

Tabel 5. Rata-Rata Rasio S/N Tensile Shear Load untuk Setiap Level

\begin{tabular}{ccc}
\hline Level & Dwell time (s) & $\begin{array}{c}\text { Plunge depth } \\
(\mathrm{mm})\end{array}$ \\
\hline 1 & 150,3 & 146,3 \\
2 & 208,0 & 154,6 \\
3 & 101,5 & - \\
4 & 141,8 & - \\
Delta & 106,5 & 8,3 \\
Rank & 1 & 2 \\
\hline
\end{tabular}

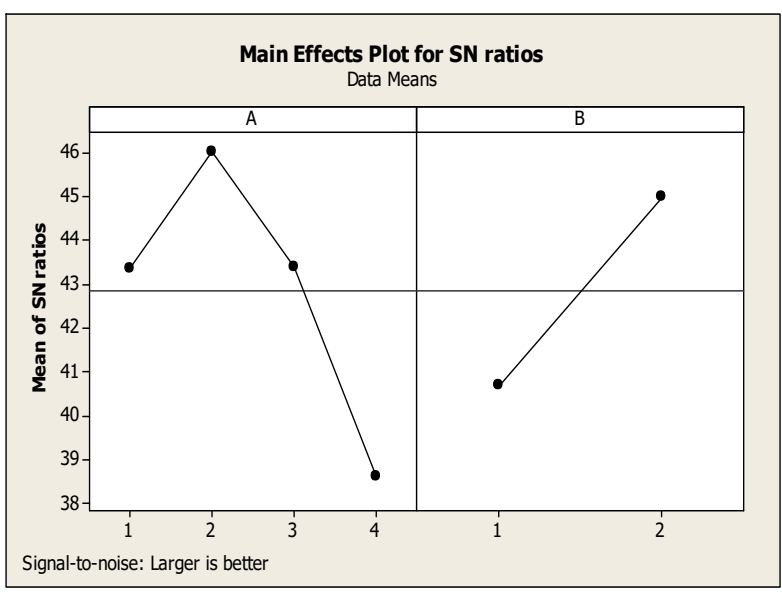

Gambar 3. Plot Grafik Pada Masing-Masing Level Parameter Proses Pengelasan $\mu$ FSSW

Tabel 6. Hasil Analisis Variansi (ANOVA)

\begin{tabular}{llllllll}
\hline Source & DF & SS & MS & SS $^{\prime}$ & F & $\begin{array}{l}\boldsymbol{\rho}- \\
\text { value }\end{array}$ & $\begin{array}{l}\% \\
\text { kontribusi }\end{array}$ \\
\hline A & 3 & 56,61 & 18,87 & 52,95 & 15,48 & 0,025 & 54,85 \\
B & 1 & 36,27 & 36,27 & 35,05 & 29,76 & 0,012 & 36,31 \\
Residual & 3 & 3,65 & 1,21 & 8,53 & & & 8,84 \\
Error & 7 & 96,54 & & & & & 100,00 \\
Total & 7 & & & & & \\
\hline
\end{tabular}

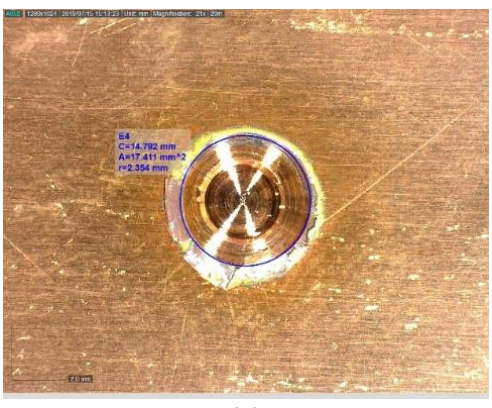

(a)

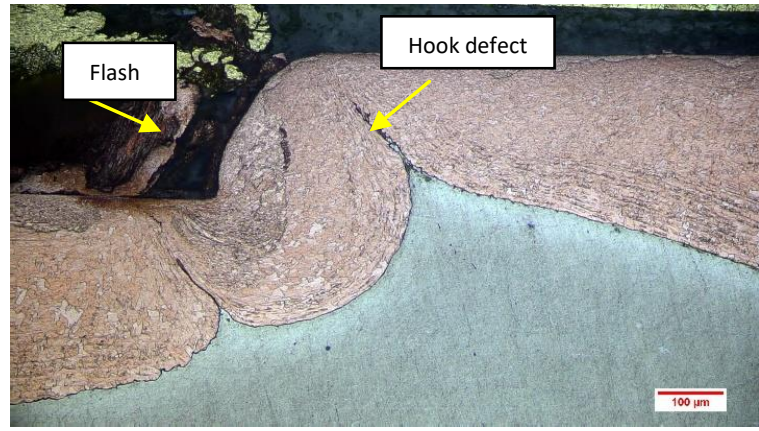

(b)

Gambar 4. a) Hasil Sambungan Pengelasan $\mu$ FSSSW;

b) Struktur Mikro Material A1100/Cu1100P pada Kombinasi Optimal Menggunakan Parameter Dwell Time $5 \mathrm{~s}$ dan Plunge Depth $0,7 \mu \mathrm{m}$

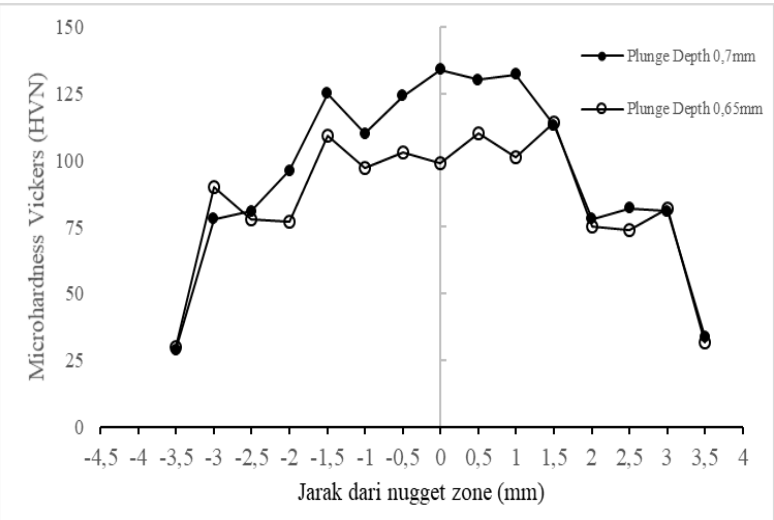

Gambar 5. Distribusi Kekerasan Menggunakan Microhardness Vickers pada Dwell Time 5 s dengan Plunge Depth $0,7 \mathrm{~mm}$ dan $0,65 \mathrm{~mm}$

Hasil sambungan dan struktur mikro pengelasan $\mu$ FSSW yang ditunjukkan pada Gambar 4 menunjukkan bahwa terjadi bonding yang cukup baik pada kondisi pengelasan, bahkan tidak terlihat adanya retakan dan intermetallic compound. Hanya saja ada sedikit flash dan hook defect yang terjadi pada kondisi pengelasan tersebut. Hasil distribusi kekerasan yang ditampilkan pada Gambar 5 menunjukkan bahwa pada plunge depth $0,7 \mathrm{~mm}$ lebih besar daripada plunge depth $0,65 \mathrm{~mm}$. Secara keseluruhan pada nugget zone memiliki nilai kekerasan yang lebih besar, karena pada nuget zone terjadi kenaikan temperature dan deformasi plastis selama proses pengelasan berlangsung yang menyebabkan rekristalisasi dinamik, sehingga hal ini dapat mereduksi ukuran butir di daerah nuget zone [2, 15]. Kekerasan terendah terjadi pada lokasi 4 sampai 4,5 dari nugget zone, di mana material mengalami pelunakan saat pengelasan [16].

\section{KESIMPULAN}

Hasil penelitian menunjukkan penggunaan metode Taguchi pada proses micro friction stir spot welding $(\mu \mathrm{FSSW})$ pada material A1100/Cu1100P, dapat disimpulkan sebagai berikut: 
1. Penggunaan metode Taguchi mampu meningkatkan performansi nilai tensile shear load pada prses pengelasan micro friction stir spot welding $(\mu \mathrm{FSSW})$ pada material aluminium A1100 dan Cu1100P.

2. Parameter proses yang digunakan baik dwell time dan plunge depth merupakan parameter proses yang signifikan.

3. Dwell time merupakan kontribusi yang paling besar dalam meningkatkan tensile shear load.

4. Kombinasi optimum yang dapat menghasilkan respon yang maskimum, yaitu parameter proses plunge depth pada $0,7 \mathrm{~mm}$ dan dwell time pada $5 \mathrm{~s}$, di mana dihasilkan tensile shear load sebesar $265,12 \mathrm{~N}$.

5. Hasil pengamatan struktur mikro menggunakan kombinasi optimal tidak menunjukkan adanya intermetallic compound yang bersifat keras dan getas. Selain itu dari struktur mikro menunjukkan indikasi adanya flash dan hook defect.

\section{UCAPAN TERIMA KASIH}

Terima kasih kepada Direktorat Riset dan Pengabdian Masyarakat, Direktorat Jenderal Penguatan Riset dan Pengembangan, Kementerian Ristek, Teknologi dan Pendidikan Tinggi yang telah memberikan bantuan dana hibah Penelitian Dosen Pemula (PDP) sesuai dengan kontrak penelitian nomor 43/AKM/MONOPNT/2019,No.225/SP2H/LT/DRPM/ 2019 dan surat keputusan nomor 050/KP/LPKTITI/IV/2019 Tanggal 27 Maret 2019. Selain itu, penulis juga mengucapkan terima kasih kepada seluruh staf Laboratorium Teknologi Manufaktur dan Otomasi Departemen Teknik Mesin Universitas Indonesia yang telah memberikan dukungan berupa sarana terhadap penelitian yang telah dilakukan.

\section{REFERENSI}

[1] C. Dawes, An introduction to friction stir welding and its development, 1995.

[2] R. S. Mishra, and Z. Y. Ma, Friction stir welding and processing, Materials Science and Engineering: R: Reports, vol. 50, no. 1, 2005, pp. $1-78,2005 / 08 / 31 /$.

[3] A. S. Baskoro, A. A. D. Nugroho, D. Rahayu, Suwarsono, G. Kiswanto, and W. Winarto, Effects of Welding Parameters in Micro Friction Stir Lap Welding of Aluminum A1100, Advanced Materials Research, vol. 789, 2013, pp. 356-359.

[4] L. Zhou, G. H. Li, R. X. Zhang, W. L. Zhou, W. X. He, Y. X. Huang, and X. G. Song, "Microstructure evolution and mechanical properties of friction stir spot welded dissimilar aluminum-copper joint," Journal of Alloys and Compounds, vol. 775, 2019, pp. 372-382, 2019/02/15/.

[5] M. Tutar, H. Aydin, C. Yuce, N. Yavuz, and A. Bayram, The optimisation of process parameters for friction stir spot-welded AA3003-H12 aluminium alloy using a Taguchi orthogonal array, Materials \& Design, vol. 63, 2014, pp. 789-797.

[6] A. S. Baskoro, Suwarsono, G. Kiswanto, and W. Winarto, Effects of High Speed Tool Rotation in Micro Friction Stir Spot Welding of Aluminum A1100, Applied Mechanics and Materials, vol. 493, 2014, pp. 739-742.

[7] A. H. Plaine, A. R. Gonzalez, U. F. H. Suhuddin, J. F. dos Santos, and N. G. Alcântara, The optimization of friction spot welding process parameters in AA6181-T4 and Ti6A14V dissimilar joints, Materials \& Design, vol. 83, 2015, pp. 36-41, 2015/10/15/

[8] K. Kamal Babu, K. Panneerselvam, P. Sathiya, A. Noorul Haq, S. Sundarrajan, P. Mastanaiah, and C. V. Srinivasa Murthy, Parameter optimization of friction stir welding of cryorolled AA2219 alloy using artificial neural network modeling with genetic algorithm, The International Journal of Advanced Manufacturing Technology, vol. 94, 2018, no. 9, pp. 3117-3129, 2018/02/01.

[9] M. K. Abbass, S. K. Hussein, and A. A. Khudhair, Optimization of Mechanical Properties of Friction Stir Spot Welded Joints for Dissimilar Aluminum Alloys (AA2024-T3 and AA 5754-H114), Arabian Journal for Science and Engineering, vol. 41, no. 11, 2016, pp. 4563-4572, 2016/11/01

[10] G. S. Peace, Taguchi methods: a hands-on approach: Addison Wesley Publishing Company, 1993.

[11] H. Badarinarayan, Y. Shi, X. Li, and K. Okamoto, Effect of tool geometry on hook formation and static strength of friction stir spot welded aluminum 5754-O sheets, International Journal of Machine Tools and Manufacture, vol. 49, no. 11, 2009, pp. 814-823, 2009/09/01/.

[12] S.-O. Yoon, M.-S. Kang, Y.-J. Kwon, S.-T. Hong, D.-H. Park, K.-H. Lee, C.-Y. Lim, and J.D. Seo, Influences of tool plunge speed and tool plunge depth on friction spot joining of AA5454-O aluminum alloy plates with different thicknesses, Transactions of Nonferrous Metals Society of China, vol. 22, 2012, pp. 629-s633, 2012/12/01/,

[13] Z. Zhang, X. Yang, J. Zhang, G. Zhou, X. Xu, and B. Zou, Effect of welding parameters on microstructure and mechanical properties of friction stir spot welded 5052 aluminum alloy, Materials \& Design, vol. 32, no. 8, 2011, pp. 4461-4470, 2011/09/01/

[14] V. X. Tran, J. Pan, and T. Pan, Effects of processing time on strengths and failure modes of dissimilar spot friction welds between aluminum 5754-O and 7075-T6 sheets, Journal of Materials Processing Technology, vol. 209, no. 8, 2009, pp. 3724-3739, 2009/04/21/ 
[15] K. Zhao, Z. Liu, B. Xiao, and Z. Ma, Friction stir welding of carbon nanotubes reinforced Al$\mathrm{Cu}-\mathrm{Mg}$ alloy composite plates, Journal of Materials Science \& Technology, vol. 33, 2017, no. 9, pp. 1004-1008, 2017/09/01/

[16] G. Li, L. Zhou, W. Zhou, X. Song, and Y. Huang, Influence of dwell time on microstructure evolution and mechanical properties of dissimilar friction stir spot welded aluminum-copper metals, Journal of Materials Research and Technology, vol. 8, no. 3, 2019, pp. 2613-2624, 2019/05/01/ 